\title{
SPOTLIGHT OU A BUSCA DA HISTÓRIA: MÍDIA E NARRATIVAS DO SILÊNCIO
}

José Cardoso Ferrão ${ }^{1}$

Era uma vez sete crianças que foram abandonadas numa floresta pelos pais, que não lhes podiam mais dar comida. Guiadas pelo irmão caçula, tão pequenino quanto um dedo polegar, foram parar na casa de um gigante. A esposa do homenzarrão atendeu à porta e logo os advertiu que era costume de o marido comer criancinhas. Os meninos, entretanto, não tiveram escolha: ou morriam na floresta devorados pelos lobos, ou arriscariam a sorte, mesmo sabendo que o ogro poderia comê-los. À noite, quando o monstro descobriu as pequenas presas em casa, mandou a esposa alimentá-los e colocá-los para dormir, na esperança de saboreá-los no dia seguinte. Mas, numa manobra de astúcia comandada pelo Polegar, os irmãos conseguiram escapar do malvado e fugiram para a floresta. O gigante lhes bateu atrás, mas o caçula, o menor deles e o mais astuto, conseguiu ludibriar novamente o mais forte, fazê-lo adormecer, roubar sua bota encantada, voltar à casa do ogro e ainda tirar-Ihe toda a fortuna, o que, enfim, garantiu o sustento da família dos meninos famintos ${ }^{2}$.

“Le petit Poucet" pertence ao imenso repertório de histórias dos camponeses franceses do Antigo Regime, recolhidas e recontadas por Charles Perrault. Os tempos que antecediam à Revolução eram bem difíceis para quem vivia na fronteira entre a pobreza e a miséria. Os contos populares são "documentos históricos (...) que retratavam um mundo de brutalidade nua e crua", nos explica Robert Darnton (1986, p. 26,29). Às vezes apelando para a imaginação e a fantasia, outras vezes usando de hipérboles para superdimensionar requintes de crueldade, essas histórias são representativas de um tempo e uma ordem social conturbados, de muita fome, escassez, epidemias e luta pela sobrevivência. São narrativas que jazem esquecidas e soterradas pela "história dos eventos", aquela ocupada com a crônica das gestas dos reis, das batalhas e conquistas, do troca-troca de ministros, das intrigas da corte (id. ibid., p. 41). Mas o povo comum, como assim o denominam os historiadores culturais, produzia suas próprias histórias e não prescindia delas. Sabia que, para além do silêncio das florestas ameaçadoras e dos cronistas oficiais, a experiência precisava ser narrada para ser compreendida. Darnton nos ensina que os contos populares franceses do Setecentos eram, sim, entendidos por quem narrava e quem ouvia. Os pequeninos sabiam identificar seus inimigos nas histórias que contavam e ouviam - e eles eram bem reais: dos lobos que rondavam as matas aos bandidos que saqueavam suas casas, aos ricos e poderosos que os mantinham sob mãos de ferro. "Não exigia nenhum grande voo de imaginação vê-los como verdadeiros tiranos (...) [Os oprimidos] não matam gigantes numa terra imaginária, mesmo quando têm de trepar por pés de feijão para alcança-los" (id. ibid., p. 83).

\footnotetext{
${ }^{1}$ Professor do Departamento de Letras e Comunicação Social, do Instituto de Ciências Humanas e Sociais, da Universidade Federal Rural do Rio de Janeiro

2 Síntese do conto O Pequeno Polegar. In: PERRAULT, GRIMM, ANDERSEN \& outros. Contos de fada. Rio de Janeiro: Zahar, 2010.
} 
Há sentidos inscritos no invisível. A vida pede para ser contada. "Tudo o que nos resta a fazer é encontrar a história", relembra um outro narrador, desta vez um repórter investigativo de uma ex-comunidade puritana da Nova Inglaterra ${ }^{3}$. É esta necessidade da narrativa, atrelada à ética jornalística herdeira das Luzes, que nos pode conduzir a uma reflexão acerca de uma história midiática do nosso tempo. Boston, estado americano de Massachussets, ano de 2001. Um padre católico havia molestado várias crianças na cidade 4 . A notícia fora dada numa coluna do prestigiado Boston Globe, para o qual trabalhava nosso repórter. Mas o jornal ganha um novo editor chefe, que acha que a história acerca do abuso sexual e espiritual dos menores, de fato, ainda não tinha sido encontrada. Seus novos colegas retrucam, embora terminem por ser convencidos do imperativo de uma investigação mais aprofundada, que acaba sendo conferida a uma equipe de quatro seletos jornalistas do periódico, a Spotlight, responsável por temas de maior fôlego. Cinco meses de exaustivo trabalho dão origem a uma série de 600 reportagens sobre o esquema de acobertamento pela Igreja Romana de centenas de casos de pedofilia cometidos por seus padres. A grande cobertura do Globe, que na época recebeu o prêmio Pulitzer, mais tarde foi usada como estudo de caso na Escola de Jornalismo da Universidade de Columbia, antes de parar nas mãos de produtores de Hollywood. O resultado foi o longa-metragem homônimo Spotlight, uma história cinematográfica de gigantes e pequenos-polegares do nosso tempo, não menos ancorada no real e recém-premiada com o Oscar.

Spotlight é uma meta-narrativa, em duas instâncias: primeiro, porque fala da não escapatória do homem de dar sentido ao cotidiano vivido, através do ato de contar; segundo, porque é a história de uma outra história. Uma cena emblemática do filme é quando o editor Robbie Robinson e a repórter Sacha Pfeiffer vão, mais uma vez, à procura de um advogado conhecido pelos acordos secretos que fazia envolvendo padres e vítimas, Eric Macleish, que o tempo todo relutava em fornecer informações aos jornalistas. MacLeish negociara diretamente com os advogados da Arquidiocese de Boston, numa espécie de "mediação privada", sem passar pela Justiça e, óbvio, bem ao largo da mídia. O recado parece claro: A Igreja paira sobre a sociedade. Ela não precisa de mediação. Está acima dos poderes, dos meios e das linguagens. E diante

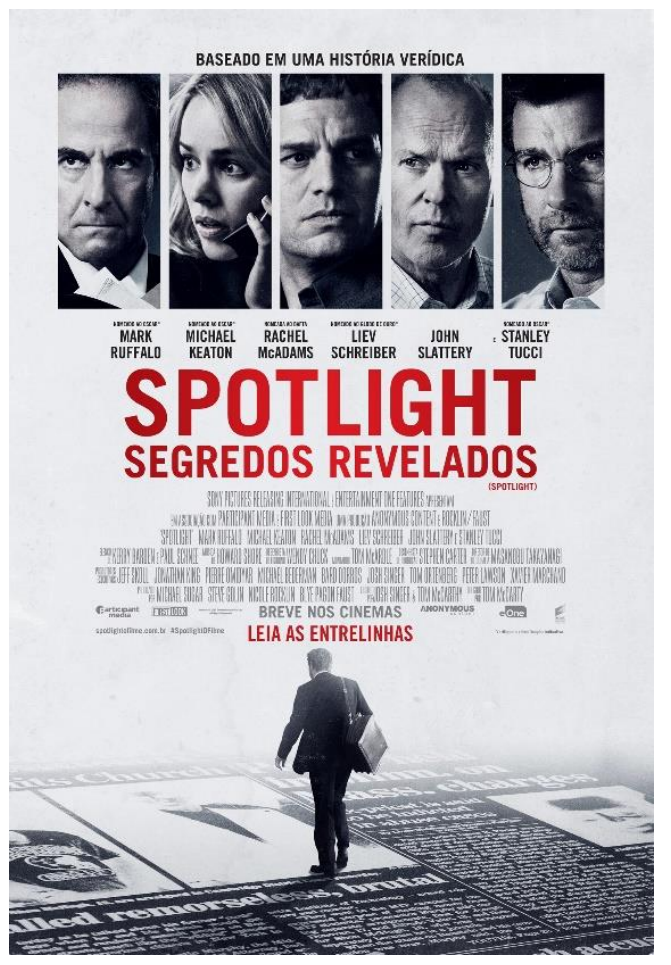

\footnotetext{
${ }^{3} \mathrm{~A}$ afirmativa é do jornalista Michael Rezendes, em entrevista coletiva com seus colegas de trabalho da época da produção da série de reportagens sobre a Arquidiocese de Boston e os casos de pedofilia cometidos por padres católicos. As informações sobre o processo que deu origem ao longa-metragem dirigido por Tom McCarthy a partir da série de reportagens do jornal Boston Globe foram extraídas da mesma gravação, disponível em: https://www.youtube.com/watch?v=8J04MhQqGIA. Acesso em 02.04.2016.

${ }^{4}$ Segundo a matéria publicada em 06.01.2002, depois da investigação que deu o prêmio Pulitzer aos jornalistas, foram mais de 130 vítimas somente do padre John Geoghan, dentre elas uma criança de apenas quatro anos de idade. Disponível em: https://www.bostonglobe.com/news/special-reports/2002/01/06/churchallowed-abuse-priest-for-years/cSHfGkTIrAT25qKGvBuDNM/story.html. Acesso em 20.03.2016.
} 
da insistência evasiva do advogado para quem "a Igreja é jogo duro", o editor da Spotlight lança o desafio: "Temos duas histórias aqui. Uma sobre o clero degenerado e outra sobre um bando de advogados que fez do abuso infantil uma indústria. Qual das duas quer que escrevamos? Porque alguma nós vamos escrever" 5 .

Este parece ser o mote de todo o filme. E é aí que está o sentido midiático e comunicacional que se lhe pode atribuir: a busca da história. Ela existe no silêncio. O trabalho non-stop dos repórteres, sentados às suas mesas, lavando a louça de casa, revirando documentos, vagando pelas ruas, comendo apressados sua junk food, é um tormento solitário. É uma luta com as palavras, como bem disse o poeta Drummond, mas também contra o cansaço, contra a Igreja que, na escuridão da noite, parece desfazer os fios da trama de Penélope, contra a exigência da velocidade jornalística e do imediatismo da novidade, além de pressões de toda ordem.

É assim que são (ou deveriam ser) gestadas as histórias que interessam. Até porque, se a narrativa se confunde com a ação humana, como diz Paul Ricoeur, a história precisa respeitar o deslocamento dos atores no espaço-tempo e o sentido que produzem, quer dizer, tanto o movimento de quem faz quanto o de quem conta. Sem dúvida, num futuro bem próximo, o texto pronto, mas que é sempre inacabado porque está à espera de um leitor para com ele negociar sentidos, será uma espécie de Catedral de Cantuária ou de Compostela, em que dormem, respectivamente, Thomas Beckett e Santiago, destino final de incansáveis peregrinos. No Boston Globe, ela será publicada no domingo da Epifania do Senhor, num ato e momento metafóricos, em que se manifestará ao mundo dos (in-)crédulos. Mas a grande reportagem existe enquanto ação silenciosa e sofrida, que se faz nas paragens, nas conversas ao pé da lareira das hospedarias, nas escolhas difíceis e consequentes das encruzilhadas.

É preciso gastar tempo com o silêncio, enquanto se tece e se vislumbra uma história. Spotlight como narrativa fílmica, assistida quinze anos depois da produção da matéria investigativa do Boston Globe, é a apologia do trabalho silencioso e custoso, um anti-google, um anti-admirávelmundo-novo. É a valoração do trabalho tedioso de organizar listas de padres pedófilos, a partir de uma coletânea de catálogos enfadonhos, publicados ao longo de 20 anos de atividade de uma Arquidiocese suspeita e que, aparentemente, não dizem nada. São os repórteres que, a partir dos espaços em branco do texto, do não-dito, do silêncio das páginas, acabam descobrindo um padrão de transferência de um padre de uma paróquia a outra, pelo simples registro de "licença médica". Puxa-se mais um fio a compor a trama.

O caminho é árduo: fichários, arquivos, edições antigas, fotografias, anuários, clippings, microfilmes e até informações online. Tudo parece chamar a história à existência e tirar-lhe a poeira que ameaça condená-la ao esquecimento, sob a égide do "sacro" poder. Narrar é um ato de memória. E a personagem de Phil Saviano sabe disso. Representante de uma organização de vítimas de pedofilia, procura mais de uma vez o jornal para fazer valer a justiça contra a Igreja

\footnotetext{
${ }^{5}$ SPOTLIGHT. Direção: Tom McCarthy, Produção: Blye Faust, Steve Golin, Nicole Rocklin, Michael Sugar. Hollywood, CA: 2005.
} 
opressora. Carrega debaixo do braço uma caixa de Pandora de provas, que já havia sido mandada ao Globe, mas que antes não conseguira despertar o interesse do periódico para o trabalho investigativo, assim como a lista de suspeitos também enviada anteriormente ao jornal pelo advogado MacLeish e "enterrada" pelo corpo editorial. "A informação está toda aqui", diz Saviano, mais uma vez, na sala da Spotlight.

Saviano e McLeish, vítima e advogado vendido, têm algo em comum: as personagens apontam para a necessidade iluminista da imprensa e seu poder de construção memorialística. As sociedades modernas já credenciaram o jornalismo para remexer o silêncio, lançar alguma luz às trevas, inscrever no tempo as ações humanas e, sem deixar de ser, apagar umas outras. Tal estrutura de sentimento, construída em pouco mais de dois séculos de história, desde as revoluções liberais do Setecentos, volta com força total no filme, como para lembrar, inclusive, que em tempos de velocidade, imediatismo e espetacularização do nada, os jornais - e a mídia - ainda têm algo a dizer.

No caso do Boston Globe, o que se buscou foi a mensagem, no sentido mais mcluhaniano possível. Ou seja, correu-se atrás dos princípios e linhas de força que alteraram a ordem ética e moral da relação (portanto, comunicação) mediada entre Deus e os homens, numa instituição também pecadora. Marty Baron, o novo editor-chefe, é uma espécie de McLuhan que aponta aos sonâmbulos repórteres onde está a mensagem e tenta tirá-los do entorpecimento dos que só conseguiam ver um conjunto de atos de violência e não a orquestração de uma operação nefasta e sistêmica. A notícia não eram os casos de pedofilia; eles são conhecidos desde que a lgreja é lgreja, uma instituição em que "cultura do celibato" só pode ser sinônima de "cultura do segredo". O que não se sabia, ou não se podia comprovar com tamanha exatidão, era o mecanismo deste silêncio que habitava o outro lado do trabalho investigativo, melhor dizendo, o seu objeto. "Eu acho que essa é a principal história", aponta Baron aos colegas. "Temos que focar na instituição, não nos padres individualmente. A prática e a política. Mostrem que a lgreja manipulou o sistema para esses caras se safarem. Mostrem que puseram os mesmos padres de volta nas paróquias reiteradamente. Mostrem que era sistêmico e que vinha de cima para baixo. Vamos atrás do sistema", diz Baron. Ou seja, o meio ainda estava sem mensagem.

O repórter investigativo sabe, entretanto, que sua ética o impulsiona a olhar para o silêncio como de vida curta. É preciso contar. Mas o tempo de narrar tem dia e momento certos. Não se pode despertar o gigante antes da hora. E ele tem sono profundo. "A Igreja pensa em séculos", diz o advogado honesto Mitchell Garabedian ao repórter Mike Rezendes. "Você acha que seu jornal tem recursos para encarar essa? ...", ao que o jornalista responde afirmativamente.

Uma guerra de histórias e silêncio. Os jornalistas correm atrás da narrativa e a Igreja some com os documentos judiciais que incriminam os padres, além de registros de acordos sigilosos que faz com os indivíduos e as famílias. A Arquidiocese e seus tentáculos vão até as vítimas e lhes pedem que não deem queixas. Do lado oposto ao trabalho silencioso e exaustivo dos jornalistas e do advogado Garabedian, o esquadrão do silêncio formado pela Igreja manipuladora, as famílias 
temerosas, os paroquianos envergonhados, a polícia comprometida e a justiça amordaçada tentam apagar os rastros narrativos que trariam à luz o trabalho de memória comandado pela Arquidiocese. Sim, porque apagar e lançar ao esquecimento também é um ato memorialístico.

A informação move as pessoas e gera ação. Sua ausência também. Porque ela deve estar em algum lugar: nos arquivos secretos, nos processos sigilosos, na caixa de Saviano, nas mentes e nos corpos das crianças. Do pequeno Joe, por exemplo, em cujos corpo e alma um tal padre Shanley pôde perceber que o menino era gay, além, é claro, de pertencer a uma família do tipo "problemática". Padre Shanley, segundo o depoimento da personagem Joe, era um "padre das ruas, cabelos compridos, todo moderno", e não demorou muito para que ele pudesse ler e recolher no então garoto as peças de um quebra-cabeça que reunia o segredo da homossexualidade com um lar disfuncional e vulnerável, quase que um padrão em muitas das crianças violentadas. "Sobre seus corpos", revela-nos a historiadora Arlette Farge ${ }^{6}$, "existem signos deles mesmos, de sua pessoa, de seu estado, de suas relações fluidas e esporádicas com o mundo e os que lhe são próximos na intimidade", ainda que em forma de rascunhos mal escritos e desenhados, como é o caso dos pequeninos da Boston contemporânea. São "formas de exibição identitária", nos diz Farge apoiada em Roger Chartier, que atuam como "condições de possibilidade" (2003, p. 10,18,21). Aqui, em Boston, basta o impulso narrativo, para se vislumbrar um conto favorável ao desejo (ou à tara) e, com ele, produzir uma outra história, perversa, criminosa e igualmente silenciosa, que, por sua vez, aguarda um outro trabalho de reconstrução narrativa, desta vez da jornalista Sacha Pfeiffer.

Mas a conversa que a personagem já adulta entretém com a repórter, à mesa de uma lanchonete, traz à tona uma outra questão: a da relação entre narrativa e linguagem. Percebendo a dificuldade da vítima da violência em dar nome ao que lhe ocorrera na infância, a repórter insiste: "Você pode me dizer o que aconteceu especificamente? ". Ao que Joe responde: "Especificamente, ele me molestou”. E a repórter vai além: “Joe, acho que a linguagem será muito importante aqui. Não podemos esterilizar isso. Dizer 'molestou' não basta. As pessoas precisam saber o que de fato aconteceu". O que a repórter quer, na verdade, é acessar o que o filósofo Walter Benjamin chama de "essência espiritual do homem" que habita na linguagem e que pode ser enunciada. Para isso, é necessário que a vítima rompa com o silêncio e nomeie as coisas, as ações, as pessoas, as sensações. A transformação da vida em narrativa só é possível na linguagem e no que ela tem de comunicável (BENJAMIN, 2005). Para que nasça a tão imprescindível história, a criança violentada no corpo do jovem traumatizado precisa, dolorosa e simbolicamente, conseguir vincular-se novamente ao seu outro, ao gigante perverso que lhe roubou a infância, estabelecer novamente com ele uma comunicação, para, enfim, chegar a compreender quem era ela, a criança, e quem era ele, o violador, quem eles foram no passado e quem são agora, e que possibilidades de libertação e transmutação se Ihes oferecem no fazer narrativo do tempo presente.

\footnotetext{
${ }^{6} \mathrm{~A}$ historiadora francesa trata dos rastros de escritura encontrados em cadáveres de mendigos e outros tipos marginalizados na França do século XVIII. V. Referências bibliográficas.
} 
Domingo da Epifania do Senhor. Máquinas impressoras rotativas trabalham a pleno vapor na sede do jornal. Em seguida, caminhões saem da garagem para a entrega matutina da edição daquele dia. Na casa da avó da repórter Sacha Pfeiffer, os dedos e os olhos da senhora católica percorrem em silêncio a grande reportagem do Boston Globe. Os jornalistas chegam à redação e precisam atender aos inúmeros telefonemas de vítimas que não foram alcançadas pela história. $\mathrm{O}$ círculo noticioso não para. No decorrer de 2002, a Spotlight publica mais de 600 matérias sobre o esquema de acobertamento de crimes de pedofilia pela Igreja de Roma.

Uma das histórias que formam o grande patchwork que é a grande história diz respeito a um jovem pai chamado Patrick, um dos clientes do advogado Garabedian. Morava num conjunto habitacional próximo ao Hyde Park de Boston, quando foi violentado pelo padre John Geoghan aos 12 anos, logo após o suicídio do pai, por quem não tinha lá um grande apreço. A mãe esquizofrênica cuidava dos sete filhos do casal disfuncional. O padre fora apresentado à família por uma irmã de Patrick, que o conheceu numa lanchonete, contou-lhe sobre a morte do genitor, e o levou à sua casa para uma visita. Daí, repetiram-se os convites do clérigo às crianças para tomar sorvete. "Eu não sabia o que fazer. Eu era apenas uma criança", conta Patrick ao repórter. O sobrevivente, ainda com o braço direito todo picado por agulhas, ao contrário de Joe, foi mais incisivo no depoimento ao jornalista Mike Rezendes: conseguiu nomear os golpes que sofreu no corpo e na alma. A reportagem original que deu à Spotlight o Prêmio Pulitzer também reconta as situações vividas com coragem e em detalhes.

Foi assim que o Pequeno Polegar de Boston e seus companheiros acabaram encontrando uma saída, em meio à densa e perigosa terra de gigantes. Entre uma encruzilhada e um caminho soturno, depararam-se com a narrativa.

\section{Referências bibliográficas:}

BENJAMIN, Walter. Über die Sprache überhaupt und über die Sprache des Menschen. In: Sprache und Geschichte: philosophische Essays. Stuttgart: Reclam, 2005.

DARNTON, Robert. O grande massacre de gatos e outros episódios da história cultural francesa. Rio de Janeiro: Graal, 1986.

FARGE, Arlette. Le bracelet de parchemin: l'écrit sur soi au XVIIle siècle. Paris: Bayard, 2003.

McLUHAN, Marshall. Understanding media: the extensions of man. London: Routledge, 1997.

PERRAULT, GRIMM, ANDERSEN \& outros. Contos de fada. Rio de Janeiro: Zahar, 2010. RICOEUR, Paul. Temps et récit: l'intrigue et le récit historique. Paris: Editions du Seuil, 1983, v.1.

SODRÉ, Muniz. Antropológica do espelho: uma teoria da comunicação linear e em rede. Petrópolis: Vozes, 2010. 